\title{
SELETIVIDADE DE HERBICIDAS APLICADOS EM PRÉ-EMERGÊNCIA SOBRE CULTIVARES DE BATATA $\left({ }^{1}\right)$
}

\author{
JOSÉ MUNHOZ FELIPE ( $\left.{ }^{2}\right)$; DAGOBERTO MARTINS $\left({ }^{3 *}\right)$; NEUMÁRCIO VILANOVA DA COSTA $\left({ }^{2}\right)$
}

\begin{abstract}
RESUMO
O presente trabalho foi realizado na Estação Experimental Agrícola da BASF S.A., situada na rodovia SP 310, km 144, no município de Santo Antonio da Posse-(SP), em área de Latossolo Vermelho distrófico com textura média. Quatro experimentos foram desenvolvidos com o objetivo de avaliar a seletividade dos herbicidas dimethenamid, metribuzin e linuron, aplicados em diferentes doses, na condição de préemergência, sobre as características de produção e qualidade dos tubérculos de quatro cultivares de batata (Solanum tuberosum L.). Utilizou-se, em todos os experimentos, o delineamento experimental de blocos ao acaso, com cinco repetições e parcelas de $21 \mathrm{~m}^{2}(3 \times 7 \mathrm{~m})$. Os tratamentos utilizados foram: testemunha capinada, dimethenamid nas doses de 0,75, 1,50 e 3,00 $\mathrm{kg} \mathrm{ha}^{-1}$, metribuzin a 0,48 e 0,72 $\mathrm{kg} \mathrm{ha}^{-1}$ e linuron a 1,50 e 2,00 kg ha-1. Foram realizadas três avaliações visuais de fitotoxicidade aos 24, 31, e 42 dias após a aplicação (DAA). A severidade das injúrias visuais verificadas nas plantas das diferentes cultivares de batata foi dependente do herbicida, da dose aplicada e da cultivar utilizada. O herbicida dimethenamid, na dose de $3,00 \mathrm{~kg} \mathrm{ha}^{-1}$, foi o tratamento que proporcionou as maiores porcentagens visuais de área foliar injuriada, no entanto tais sintomas desapareceram completamente aos 42 DAA. Nenhum tratamento com herbicida interferiu negativamente na produção de tubérculos, na massa seca dos tubérculos e no tamanho final dos tubérculos colhidos.
\end{abstract}

Palavras-chave: Solanum tuberosum, fitotoxicidade, dimethenamid, metribuzin e linuron.

\section{ABSTRACT \\ SELECTIVITY OF HERBICIDES APPLIED IN PRE-EMERGENCE ON DIFFERENT POTATO CULTIVARS}

The present research was carried out at the Agricultural Experimental Station of BASF S.A., located in the SP 340, highway km 144, Santo Antonio de Posse, State of São Paulo, on a dystrophic dark Red Latosol (Rhodic Haplustox) area, with medium texture. Four experiments were carried out to evaluate the selectivity of the herbicides dimethenamid, metribuzin and linuron, applied at different rates, in the preemergence condition, in the production characteristics and quality of the tubers of four cultivars of potato (Solanum tuberosum L.). In each experiment was used, a randomized block experimental design, with five replications and plots of $21 \mathrm{~m}^{2}(3 \times 7 \mathrm{~m})$. The treatments were: hand weeded, dimethenamid at rates of $0.75 ; 1.50$ and $3.00 \mathrm{~kg} \mathrm{ha}^{-1}$, metribuzin at 0.48 and $0.72 \mathrm{~kg} \mathrm{ha}^{-1}$ and linuron at 1.50 and $2.00 \mathrm{~kg} \mathrm{ha}^{-1}$. Three visual injury evaluations were done at 24.31 and 42 days after aplication (DAA). The severity of crop the injury in the different cultivars, was directly correlated with the herbicides, the rate applied and the potato cultivars. The herbicide dimethenamid at 3,00 kg ha-1 showed the highest percentage of leaf damage, although these symptoms disappeared completely at 42 DAA. None herbicidal treatment interfered negatively in yield, dry matter content of the potatoes tuber, and in the final size of the potatoes tuber.

Key wods: Solanum tuberosum, phytotoxicity, dimethenamid, metribuzin, linuron.

$\left.{ }^{1}\right)$ Recebido para publicação em 29 de abril de 2005 e aceito em $1 .^{\circ}$ de agosto de 2006.

$\left(^{2}\right)$ Pós-graduando, Departamento de Produção Vegetal-Agricultura, UNESP/FCA, Botucatu-(SP).

( $\left.{ }^{3}\right)$ Departamento de Produção Vegetal-Agricultura, UNESP/FCA. Caixa Postal 237, 18603-970, Botucatu-(SP). * Autor correspondente. E-mail: dmartins@fca.unesp.br 


\section{INTRODUÇÃO}

Como toda cultura agrícola, a batata (Solanum tuberosum L.) está sujeita a uma série de fatores, bióticos e abióticos, que influenciam seu crescimento, desenvolvimento e produtividade econômica. Dentre esses fatores, destaca-se a interferência propiciada pela convivência da cultura com as plantas daninhas, as quais, segundo LuTMAN (1992), competem por água, luz e nutrientes, estando o grau de severidade dessa competição relacionado com o conjunto de espécies e densidade da comunidade infestante.

Na cultura da batata, os possíveis métodos de manejo de plantas daninhas seriam o manual, por meio de capinas com enxadas; o mecânico, com auxílio de cultivadores e o químico, por meio da aplicação de herbicidas. Contudo, o químico é o que prevalece nas propriedades com produção comercial. Ressalta-se que o processo de amontoa consiste em um modo de controle mecânico de plantas daninhas e utilizado na maioria das áreas de produção da cultura.

Kunz et al. (1997) citam que a produtividade das lavouras de batata aumentou 39\% devido ao uso de insumos modernos, entre eles os herbicidas. BREMER (1966) comenta que o cultivo mecânico pode reduzir em $5 \%$ a produção de tubérculos, quando comparado com o uso de herbicidas. LutMan (1992), por sua vez, cita que o controle mecânico danificou o sistema radicular, compactou o solo e reduziu a produtividade, enquanto ElLIOT (1995) comentou que a produtividade de tubérculos com o uso de paraquat foi $4 \mathrm{tha}^{-1}$ superior à obtida no controle de plantas daninhas com o uso de cultivadores.

Apesar do controle químico oferecer certas vantagens sobre os demais métodos de controle de plantas daninhas, deve-se ressaltar que este só pode ser praticado com o uso de herbicidas seletivos para a cultura. Segundo Velini et al. (2000), para ser recomendado de forma definitiva e indiscriminada para uma determinada cultura, um herbicida deve demonstrar seletividade aos cultivares mais comuns dessa cultura. Esses autores definem seletividade como a capacidade de um determinado herbicida em eliminar as plantas daninhas encontradas em uma cultura sem reduzir-lhe a produtividade.

ANDERSOn (1981) define seletividade como o controle de algumas plantas daninhas sem ocasionar injúrias a outras plantas de interesse comercial; observa-se que, de maneira geral, pode ser aplicado a todas as culturas. Entretanto, ressalta-se que, especialmente para as plantas produtoras de tubérculos, deve-se avaliar além dos efeitos na produtividade, a qualidade do produto final. $\mathrm{Na}$ literatura, verificam-se alguns exemplos de herbicidas seletivos para essa cultura e deve-se considerar que em cultivares diferentes, de uma mesma espécie, pode haver sensibilidade diferenciada a um determinado herbicida. Munzert e KeEs (1990) concluíram que de um total de 72 cultivares de batata, 45 foram tolerantes ao metribuzin, 23 foram moderadamente sensíveis e quatro foram altamente sensíveis. No caso de bentazon, 56 foram totalmente tolerantes, 15 moderadamente sensíveis e uma altamente sensível.

SHARPE et al. (1994) citam que os herbicidas prometryne, metribuzin e linuron foram amplamente utilizados na cultura da batata nos campos da Romênia, com boa seletividade à solanácea. Ainda, segundo esses pesquisadores, o dimethenamid também foi seletivo a essa cultura. Chirita (1995) comentou que o herbicida dimethenamid, aplicado de forma isolada, e as misturas de alachlor + bentazon, oltchim 39 B + clethodim + actipron e metribuzin + dimethenamid, foram seletivos à cultura de batata.

Ressalta-se que os herbicidas linuron e metribuzin são registrados para a cultura da batata no Brasil, enquanto o herbicida dimethenamid é registrado para as culturas de soja, milho e cana-deaçúcar (RodRigues e Almeida, 1998).

O presente trabalho teve como objetivo avaliar a seletividade dos herbicidas dimethenamid, metribuzin e linuron, aplicados em diferentes doses, na condição de pré-emergência, sobre as características de produção e qualidade dos tubérculos de quatro cultivares de batata.

\section{MATERIAL E MÉTODOS}

Os experimentos foram desenvolvidos na Estação Experimental Agrícola da BASF S.A., situada na rodovia SP 340, $\mathrm{km} \mathrm{144,} \mathrm{no} \mathrm{município} \mathrm{de} \mathrm{Santo}$ Antonio de Posse (SP). O solo foi classificado como Latossolo Vermelho distrófico com textura média. As características químicas e físicas do solo da área experimental estão descritas na tabela 1.

O solo foi preparado segundo o sistema convencional, com uma aração e duas gradagens. Em seguida, procedeu-se à abertura dos sulcos de plantio a uma profundidade de $30 \mathrm{~cm}$, utilizando-se um sulcador tratorizado. De acordo com a análise de solo, não foi necessário o uso de calcário, sendo realizado somente a adubação de plantio com 50-300-80 kg ha ${ }^{-1}$ de N-P-K respectivamente. 
Tabela 1. Características químicas e físicas do solo da área experimental. Santo Antonio de Posse-(SP), 1998

\begin{tabular}{|c|c|c|c|c|c|c|c|c|c|}
\hline \multirow[b]{2}{*}{$\mathrm{pH}\left(\mathrm{CaCl}_{2}\right)$} & \multicolumn{9}{|c|}{ Característica química } \\
\hline & M.O. & $P_{\text {resina }}$ & $\mathrm{H}+\mathrm{AL}$ & K & $\mathrm{Ca}$ & $\mathrm{Mg}$ & SB & CTC & $\mathrm{V} \%$ \\
\hline & -( & $\bar{u}$ & $\longrightarrow$ & 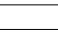 & 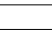 & $\operatorname{nol}_{\mathrm{c}} \mathrm{dr}$ & & & \\
\hline \multirow[t]{5}{*}{5,4} & 2,8 & 9,5 & 22 & 4,8 & 69 & 13 & 86,8 & 107,8 & 79,8 \\
\hline & \multicolumn{9}{|c|}{ Característica física } \\
\hline & \multicolumn{2}{|c|}{ Areia grossa } & \multicolumn{3}{|c|}{ Areia fina } & Limo & \multicolumn{3}{|c|}{ Argila } \\
\hline & \multicolumn{2}{|c|}{ 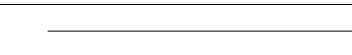 } & & 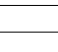 & & 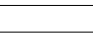 & & & \\
\hline & \multicolumn{2}{|c|}{133} & \multicolumn{3}{|c|}{539} & 55 & \multicolumn{3}{|c|}{273} \\
\hline
\end{tabular}

As batatas-semente estavam em brotação plena, sem dominância apical e foram plantadas manualmente no espaçamento de $75 \mathrm{~cm}$ entre linhas, colocando-se três batatas por metro a uma profundidade de $15 \mathrm{~cm}$. Aos 42 dias após o plantio, realizou-se uma adubação de cobertura com $50 \mathrm{~kg}$ ha1 de $\mathrm{N}$, usando nitrato de amônio, seguida pela prática da amontoa.

Os tratamentos utilizados foram com dimethenamid (Zeta 900) a 0,75, 1,50 e 3,00 $\mathrm{kg} \mathrm{ha}^{-1}$; metribuzin (Sencor 480) a 0,48 e $0,72 \mathrm{~kg} \mathrm{ha}^{-1}$; linuron (Afalon SC) a 1,5 e 2,00 kg ha-1 e uma testemunha sem aplicação de herbicidas, mantida livre da infestação de plantas daninhas por meio de capinas manuais. As cultivares foram consideradas separadamente, em quatro experimentos com delineamento experimental de blocos casualizados, com cinco repetições e parcelas de $21 \mathrm{~m}^{2}(3 \times 7 \mathrm{~m})$. Foram utilizadas as cultivares Bintje, Monalisa, Atlantic e Achat.

A aplicação dos herbicidas foi realizada um dia após o plantio, em pré-emergência da cultura, e das plantas daninhas, com auxílio de um pulverizador costal pressurizado a ar comprimido, na pressão de 2,5 bar, acoplado a uma barra de sete bicos de jato plano tipo XR110.02VS, o que proporcionou um consumo de calda de $200 \mathrm{~L}^{-1}$. Na tabela 2, estão descritos o horário de aplicação e a condição de algumas características edafoclimáticas durante esse período.

Durante o ciclo da cultura, além dos referidos tratamentos de herbicidas e de aplicações de inseticidas, fungicidas e bactericidas no intuito de evitar ataque de pragas e doenças, foram realizadas três capinas para evitar a interferência da plantas daninhas. A umidade do solo foi mantida por meio de irrigações periódicas baseadas em leituras pluviométricas e nos requerimentos da cultura.
Tabela 2. Condições edafoclimáticas, registradas por ocasião da aplicação dos herbicidas. Santo Antonio de Posse-(SP), 1998

\begin{tabular}{lcc}
\hline Características & Início & Término \\
\hline Horário de Aplicação & 9h20min & 12h5min \\
Condição do solo & Úmido & Úmido \\
Temperatura do ar $\left({ }^{\circ} \mathrm{C}\right)$ & 27 & 31 \\
Temperatura do solo $\left({ }^{\circ} \mathrm{C}\right)$ & 22 & 23 \\
Umidade relativa do ar $(\%)$ & 82 & 67 \\
Velocidade do vento $\left(\mathrm{m} \mathrm{s}^{-1}\right)$ & 0,8 & 1,2 \\
Intensidade Luminosa $(\mathrm{Lux})$ & 120.000 & 100.000
\end{tabular}

Foram realizadas avaliações visuais de fitotoxicidade aos 24, 31, e 42 dias após a aplicação (DAA), com uso de uma escala percentual de notas variando entre 0 (zero) e 100 (cem), onde 0 implica ausência de quaisquer injúrias e 100, a morte da planta.

A colheita foi realizada manualmente aos 116 dias após o plantio (DAP), retirando-se todas as plantas da parcela $\left(21 \mathrm{~m}^{2}\right)$. Determinou-se a produção através da avaliação da massa de todos os tubérculos colhidos por tratamento. Em seguida, retirou-se uma amostra de $8 \mathrm{~kg}$ de tubérculos por parcela para avaliação de tamanho, com auxílio de um classificador manual de pequena dimensão, usado exclusivamente para experimentação, de propriedade do Instituto Agronômico (IAC), de Campinas, estabelecendo a seguinte classificação, com base no diâmetro: tipo 1, maior que $54 \mathrm{~mm}$; tipo 2, entre 48 e $54 \mathrm{~mm}$; tipo 3, entre 41 e $47 \mathrm{~mm}$; tipo 4 , ente 34 e $40 \mathrm{~mm}$; tipo 5 , menor que $33 \mathrm{~mm}$. Para a análise estatística, utilizaram-se somente os dados dos tubérculos do tipo 1. Determinou-se, ainda, a massa dos tubérculos, estabelecendo sua participação percentual na amostra total. 
Com o intuito de comparar as diferenças entre as características dos tubérculos de mesmo tipo, determinaram-se o diâmetro, a largura e o comprimento de cinco tubérculos retirados aleatoriamente do grupo tipo 1. Para tal, considerouse por diâmetro a maior medida na largura, e largura, a menor medida desta.

Os dados foram submetidos à aplicação do teste F na análise da variância e as médias foram comparadas pelo teste "Tukey" ( $p>0,05)$, sendo os valores em porcentagem transformados em arco seno $\sqrt{\mathrm{x} / 100}$.

\section{RESULTADOS E DISCUSSÃO}

Na tabela 3, estão apresentados os resultados das avaliações visuais da fitotoxicidade provocada pelos herbicidas nas quatro cultivares de batata. Observou-se que, na primeira avaliação (24 DAA), o herbicida dimethenamid, independentemente da dose utilizada, proporcionou sintomas de injúrias em todas as cultivares, com exceção da cultivar Atlantic quando tratada com a menor dose desse herbicida. Nesse mesmo período, na cultivar Bintje verificou-se leve sintoma de fitotoxidez provocado pelos herbicidas metribuzin e linuron nas doses de 0,72 e 2,00 $\mathrm{kg} \mathrm{ha}^{-1}$ respectivamente.

A cultivar Achat foi a única em que se observaram injúrias provocadas por todos os herbicidas testados. De maneira geral, os sintomas foram leves e dissiparam-se completamente aos 42 DAA.

As diferentes respostas observadas entre as cultivares quando tratados com um mesmo herbicida corroboram os trabalhos de SELLECK (1978) e MunZERT e KeEs (1990), nos quais demonstraram que as injúrias causadas em uma espécie por um determinado herbicida podem variar com a cultivar. De outra forma,
SHARPE et al. (1994) não observaram nenhum efeito fitotóxico com os herbicidas dimethenamid, metribuzin, linuron e prometryne na cultura da batata, quando aplicados em pré-emergência, demonstrando que os efeitos de injúrias em folhas são bastante variados, dependendo não só da cultivar utilizada, mas também de outros fatores, como solo e clima.

Como o presente experimento foi desenvolvido em solo de textura arenosa e os herbicidas aplicados em pré-emergência, a seletividade pode ter sido influenciada pela textura do solo, pelas chuvas ou irrigações e pela temperatura; tais fatores podem modificar o posicionamento dos herbicidas no solo, conforme relataram KLINGMAN e AsHTON (1968).

As altas precipitações pluviais sobre solos tratados com herbicidas de alta solubilidade levam ao caminhamento do produto no perfil até as camadas mais profundas, podendo atingir a faixa de desenvolvimento da cultura e, conseqüentemente, comprometer a seletividade, mas esse fato não ocorreu no presente experimento.

$\mathrm{Na}$ tabela 4, estão apresentados os valores de produção de tubérculos de cada cultivar de batata, no fim do ciclo. Apesar do aparecimento inicial de injúrias nas plantas devido ao efeito de alguns herbicidas, a produção final não foi afetada em nenhuma das cultivares.

RAPPARINI et. al. (1991) também demonstraram que pendimethalin e metribuzin, apesar de causarem injúrias foliares em batatas, não afetaram negativamente a produção nas cultivares testadas. Da mesma forma, BREMER (1966), COHICK (1973) e LUTMAN (1992) não verificaram prejuízos na produção, quando compararam os métodos químicos e mecânicos no controle de plantas daninhas na cultura da batata.

Tabela 3. Médias das porcentagens de fitotoxicidade aos 24, 31 e 42 dias após a aplicação (DAA), nos cultivares de batata avaliados, em função da aplicação de herbicidas. Santo Antonio de Posse-(SP), 1998

\begin{tabular}{|c|c|c|c|c|c|c|c|c|c|c|c|c|c|}
\hline \multirow{3}{*}{ Tratamentos } & \multirow{3}{*}{ Dose } & \multicolumn{12}{|c|}{ Fitotoxicidade } \\
\hline & & \multicolumn{3}{|c|}{ Bintje } & \multicolumn{3}{|c|}{ Monalisa } & \multicolumn{3}{|c|}{ Atlantic } & \multicolumn{3}{|c|}{ Achat } \\
\hline & & 24 DAA & $31 \mathrm{DAA}$ & 42 DAA & 24 DAA & $31 \mathrm{DAA}$ & $42 \mathrm{DAA}$ & $24 \mathrm{DAA}$ & 31 DAA & 42 DAA & 24 DAA & $31 \mathrm{DAA}$ & $42 \mathrm{DAA}$ \\
\hline & $\mathrm{kg} \mathrm{ha}^{-1}$ & & & & & & + & & & & & & \\
\hline $\begin{array}{l}\text { Testemunha } \\
\text { Capinada }\end{array}$ & - & 0,0 & 0,0 & 0,0 & 0,0 & 0,0 & 0,0 & 0,0 & 0,0 & 0,0 & 0,0 & 0,0 & 0,0 \\
\hline Dimethenamid & 0,75 & 0,8 & 0,0 & 0,0 & 0,2 & 0,0 & 0,0 & 0,0 & 0,0 & 0,0 & 1,8 & 0,6 & 0,0 \\
\hline Dimethenamid & 1,50 & 2,6 & 1,2 & 0,0 & 0,8 & 0,0 & 0,0 & 1,8 & 1,8 & 0,0 & 3,4 & 1,4 & 0,0 \\
\hline Dimethenamid & 3,00 & 5,2 & 3,4 & 0,0 & 3,6 & 2,6 & 0,0 & 3,2 & 3,2 & 0,0 & 6,6 & 0,0 & 0,0 \\
\hline Metribuzin & 0,48 & 0,0 & 0,0 & 0,0 & 0,0 & 0,0 & 0,0 & 0,0 & 0,0 & 0,0 & 0,8 & 0,0 & 0,0 \\
\hline Metribuzin & 0,72 & 0,6 & 0,0 & 0,0 & 0,0 & 0,0 & 0,0 & 0,0 & 0,0 & 0,0 & 2,8 & 0,0 & 0,0 \\
\hline Linuron & 1,50 & 0,0 & 0,0 & 0,0 & 0,0 & 0,0 & 0,0 & 0,0 & 0,0 & 0,0 & 1,6 & 0,0 & 0,0 \\
\hline Linuron & 2,00 & 0,4 & 0,0 & 0,0 & 0,0 & 0,0 & 0,0 & 0,0 & 0,0 & 0,0 & 3,6 & 0,0 & 0,0 \\
\hline
\end{tabular}


Tabela 4. Produção de tubérculos de batatas das diferentes cultivares avaliadas, ao final do ciclo. Santo Antonio de Posse (SP), 1998

\begin{tabular}{|c|c|c|c|c|c|}
\hline Tratamentos & Dose & Bintje & Monalisa & Atlantic & Achat \\
\hline & $\mathrm{kg} \mathrm{ha}^{-1}$ & & $\mathrm{th}$ & & \\
\hline $\begin{array}{l}\text { Testemunha } \\
\text { Capinada }\end{array}$ & - & 24,03 & 28,12 & 28,00 & 19,89 \\
\hline namid & 0,75 & 24,66 & 28,63 & 28,53 & 20,03 \\
\hline & 1,5 & & & & 20,34 \\
\hline & 3,0 & & & & 19,67 \\
\hline & 0,4 & & & & 19,73 \\
\hline & 0,72 & & & & 20,87 \\
\hline & 1,50 & 25 & 28,55 & 28, & 19,39 \\
\hline Linuron & 2,00 & 24,37 & 29,13 & 28,39 & 19,28 \\
\hline & - & $1,27^{\mathrm{ns}}$ & $0,34^{\mathrm{ns}}$ & $0,21^{\mathrm{ns}}$ & $0,21^{n}$ \\
\hline & . & 5,61 & 4,88 & 6,90 & 12,73 \\
\hline d.m.s. & - & 2,49 & 2,50 & 3,53 & 4,53 \\
\hline
\end{tabular}

ns: não significativo.

$\mathrm{Na}$ tabela 5, estão apresentadas as porcentagens da massa de tubérculos do tipo 1 das cultivares de batata avaliadas. No geral, observou-se que a 'Bintje' foi a cultivar com a menor porcentagem de massa de tubérculos do tipo 1 , em relação às demais cultivares avaliadas.

A 'Atlantic' foi a cultivar de maior porcentagem. Para a 'Bintje', pôde-se notar que a menor dose de dimethenamid proporcionou redução da massa de tubérculos em cerca de 42,6\%, em relação à testemunha capinada. Entretanto, não se deve atribuir a redução da massa de tubérculos a um efeito isolado do herbicida, pois essa redução não ocorreu na maior dose testada. Contudo, não houve diferenças estatísticas entre os tratamentos, o que pode expressar a tolerância dessa cultivar aos herbicidas testados.
Tabela 5. Médias da porcentagem da massa de tubérculos do tipo 1, das cultivares avaliadas. Santo Antonio de Posse-(SP), 1998

\begin{tabular}{|c|c|c|c|c|c|}
\hline \multirow{2}{*}{ Tratamentos } & \multirow[t]{2}{*}{ Dose } & Bintje & Ionalisa & Atlantic & Achat \\
\hline & & \multicolumn{4}{|c|}{ massa de tubérculos } \\
\hline & $\mathrm{kg} \mathrm{ha}^{-1}$ & & & & \\
\hline \multicolumn{6}{|l|}{$\begin{array}{l}\text { Testemunha } \\
\text { Capinada }\end{array}$} \\
\hline Dimethenamid & 0,75 & 5,8 & 50,1 & 92,6 & $51,6 \mathrm{ab}$ \\
\hline Dimethenamid & 1,50 & 12,5 & 53,2 & 90,3 & $49,3 \mathrm{~b}$ \\
\hline Dimethenamid & 3,00 & 10,8 & 49,8 & 91,0 & $46,2 \mathrm{~b}$ \\
\hline Metribuzin & 0,48 & 16,3 & 54,2 & 92,8 & $55,4 \mathrm{ab}$ \\
\hline Metribuzin & 0,72 & 8,7 & 53,5 & 91,0 & 62,3 a \\
\hline Linuron & 1,50 & 9,6 & 55,2 & 93,6 & $48,1 \mathrm{~b}$ \\
\hline Linuron & 2,00 & 14,8 & 52,1 & 94,3 & $54,7 \mathrm{ab}$ \\
\hline $\mathrm{F}_{\text {Tratamento }}$ & - & $1,95^{\mathrm{ns}}$ & $1,05^{\mathrm{ns}}$ & $0,71^{\mathrm{ns}}$ & $3,17^{*}$ \\
\hline C.V. (\%) & - & 48,78 & 19,75 & 4,16 & 12,95 \\
\hline D.M.S. & - & 9,65 & 18,04 & 6,84 & 12,01 \\
\hline
\end{tabular}

Valores em porcentagem foram transformados em arco seno vx/100. Médias seguidas de mesma letra, na coluna, não diferem estatisticamente entre si pelo teste de Tukey $(p>0,05)$.

* significativo $(p>0,05)$.

ns: não significativo.

Observou-se, nas cultivares Atlantic e Achat, a maior porcentagem de tubérculos do tipo 1 . É importante destacar que esse fato caracteriza grande uniformidade nos tubérculos, o que se constitui grande vantagem comercial. Verificou-se na cultivar Achat diferença estatística, sendo o tratamento com metribuzin, utilizado na maior dose, superior à testemunha capinada.

O diâmetro, a largura e o comprimento de tubérculos tipo 1 das cultivares Bintje e Monalisa são apresentados na tabela 6. Não foram observados diferenças estatísticas para nenhum destes parâmetros nas cultivares Bintje e Monalisa.

Tabela 6. Médias do diâmetro, largura e comprimento dos tubérculos com tamanho maior que $54 \mathrm{~mm}$, dos cultivares Bintje e Monalisa. Santo Antonio de Posse-(SP), 1998

\begin{tabular}{|c|c|c|c|c|c|c|c|}
\hline \multirow{2}{*}{ Tratamentos } & \multirow{2}{*}{ Dose } & \multicolumn{3}{|c|}{ Bintje } & \multicolumn{3}{|c|}{ Monalisa } \\
\hline & & Diâmetro & Largura & Comprimento & Diâmetro & Largura & Comprimento \\
\hline & $\mathrm{kg} \mathrm{ha}^{-1}$ & & & $\mathrm{~ms}$ & $\mathrm{n}$ & & \\
\hline Testemunha Capinada & - & 57,6 & 43,6 & 87,8 & 60,4 & 47,6 & 95,8 \\
\hline Dimethenamid & 0,75 & 58,0 & 44,4 & 87,6 & 62,6 & 48,6 & 98,2 \\
\hline Dimethenamid & 1,50 & 59,2 & 45,4 & 92,0 & 59,0 & 47,2 & 95,0 \\
\hline Dimethenamid & 3,00 & 57,6 & 43,6 & 89,8 & 60,8 & 49,6 & 96,8 \\
\hline Metribuzin & 0,48 & 58,0 & 45,6 & 94,4 & 62,6 & 49,0 & 100,6 \\
\hline Metribuzin & 0,72 & 58,8 & 45,6 & 88,0 & 65,2 & 51,2 & 105,2 \\
\hline Linuron & 1,50 & 58,8 & 43,6 & 90,4 & 63,0 & 50,0 & 99,2 \\
\hline Linuron & 2,00 & 59,4 & 44,4 & 88,4 & 62,2 & 49,6 & 96,2 \\
\hline $\mathrm{F}_{\text {Tratamento }}$ & - & $0,28^{\text {ns }}$ & $1,32^{\mathrm{ns}}$ & $0,57^{\mathrm{ns}}$ & $2,25^{\mathrm{ns}}$ & $1,35^{\mathrm{ns}}$ & $1,66^{\mathrm{ns}}$ \\
\hline C.V. (\%) & - & 5,15 & 3,94 & 7,92 & 4,55 & 5,10 & 5,87 \\
\hline d.m.s. & - & 5,38 & 3,13 & 12,71 & 5,04 & 4,47 & 10,32 \\
\hline
\end{tabular}

ns: não significativo. 
Na tabela 7, são apresentados diâmetro, largura e comprimento dos tubérculos tipo 1 das cultivares de batata Atlantic e Achat. Verificou-se que ocorreram diferenças estatísticas apenas para a característica diâmetro da cultivar Atlantic, sendo observado que entre os tratamentos com herbicida, em nenhum deles se observou tubérculos com diâmetros inferiores aos da testemunha capinada.

Tabela 7. Médias do diâmetro, largura e comprimento dos tubérculos com tamanho maior que 54 mm, dos cultivares Atlantic e Achat Santo Antonio de Posse (SP), 1998

\begin{tabular}{|c|c|c|c|c|c|c|c|}
\hline \multirow{2}{*}{ Tratamentos } & \multirow{2}{*}{ Dose } & \multicolumn{3}{|c|}{ Atlantic } & \multicolumn{3}{|c|}{ Achat } \\
\hline & & Diâmetro & Largura & Comprimento & Diâmetro & Largura & Comprimento \\
\hline & $\mathrm{kg} \mathrm{ha}^{-1}$ & 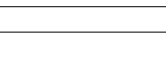 & 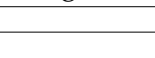 & $\mathrm{mm}$ & 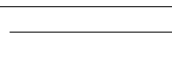 & & \\
\hline Testemunha Capinada & - & $67,2 \mathrm{c}$ & 54,8 & 72,2 & 68,2 & 52,8 & 85,0 \\
\hline Dimethenamid & 0,75 & $68,6 \mathrm{bc}$ & 53,8 & 73,6 & 64,6 & 50,8 & 82,0 \\
\hline Dimethenamid & 1,50 & $71,4 \mathrm{ab}$ & 54,4 & 75,8 & 67,6 & 50,8 & 85,2 \\
\hline Dimethenamid & 3,00 & $72,2 \mathrm{a}$ & 56,4 & 74,2 & 65,6 & 48,2 & 79,8 \\
\hline Metribuzin & 0,48 & $70,6 \mathrm{abc}$ & 56,2 & 73,8 & 65,8 & 51,2 & 82,8 \\
\hline Metribuzin & 0,72 & $73,2 \mathrm{a}$ & 55,2 & 76,8 & 63,4 & 48,6 & 79,8 \\
\hline Linuron & 1,50 & $70,6 \mathrm{abc}$ & 55,6 & 72,6 & 65,8 & 49,4 & 83,8 \\
\hline Linuron & 2,00 & $70,6 \mathrm{abc}$ & 53,8 & 72,4 & 66,8 & 50,2 & 79,8 \\
\hline $\mathrm{F}_{\text {Tratamento }}$ & - & $4,65^{* *}$ & $1,26^{\mathrm{ns}}$ & $0,78^{\text {ns }}$ & $0,93^{\mathrm{ns}}$ & $2,23^{\mathrm{ns}}$ & $0,79^{\mathrm{ns}}$ \\
\hline C.V. $(\%)$ & - & 2,81 & 3,64 & 5,64 & 5,49 & 4,46 & 6,39 \\
\hline d.m.s. & - & 3,57 & 3,59 & 7,45 & 6,47 & 4,00 & 9,45 \\
\hline
\end{tabular}

Médias seguidas de mesma letra, na coluna, não diferem estatisticamente entre si pelo teste de Tukey $(\mathrm{P}>0,05)$.

** significativo $(\mathrm{p}>0,01)$.

ns: não significativo.

\section{CONCLUSÕES}

1. A fitotoxicidade visual foi dependente da cultivar, do herbicida e da dose aplicada, e todos os sintomas de injúria dissiparam-se ao longo do ciclo da cultura, não afetando a produção e a qualidade dos tubérculos.

2. Os herbicidas dimethenamid, metribuzin e linuron, aplicados em pré-emergência, foram seletivos para as cultivares Bintje, Monalisa, Atlantic e Achat.

\section{REFERÊNCIAS}

ANDERSON, W.P. Weed Science Principles. 2.ed. St Paul: West Publication, 1981. p.575.

BREMER, P. M. The effect of cultivation on yield of the potato crop. In: BRITSH CROP PROTECTIONCONFERENCE WEED, 8., 1966, Brighton. Proceedings... Brighton,U.K: BCPC, 1966. p. 12-17.

CHIRITA, N. Research on the selectivity of some herbicidas in controlling annual weeds in a potato crop. Cercetari Agronomice in Moldova, Chisinau, v. 28, n.3-4, p.123-126, 1995. (CD-ROM).
COHICK, A. D. Sencor herbicide for the control of weeds in potatoes. Pflanzenschutz-nachr, Leverkusen, v.26, n.1, p.23-24, 1973.

ELLIOT, J. G. Development of chemical weed control in potatoes. Annual Report Arc Weed Research Organization, New Jersey/U.S.A, v. 1, p.10-14, 1995.

KLINGMAN, G. C.; ASHTON, F. M. Weed Science: principles and practices. National Academic of Science - Weed Control, Washington, v.2, p. 431-471, 1968.

KUNZ. R. P.; ZAGONEL, J.; REGHIN, M. Y.; FERREIRA, H. J. Avaliação da eficiência e seletividade de metribuzin + metolachlor e metribuzin + afametolacloro no controle de plantas daninhas em cultivares de batata (Solanum tuberosum L.) In: CONGRESSO BRASILEIRO DE OLERICULTURA, 37., 1997, Manaus. Resumos... Manaus, SBO, 1997. p. 132.

LUTMAN, P. J. W. Weeds in potatoes. In: HARRIS, P. M. The potatoes crop: the scientific basis for improvement. 2.ed. London: Chapman \& Hall, 1992. p. 373-379.

MUNZERT, M.; KEES, H. Further results for herbicide tolerance of potato cultivars. Kartoffelbau, Ribbesbüttel, v.41, n.4, p. 126-9, 1990. (CD-ROM).

RAPPARINI, G.; BARTOLINE, D.; FABBRI, M. Selectivity and degradation time of potato herbicides. Informativo Agropecuário, Belo Horizonte, v.47, n.29, p.49-57, 1991. 
RODRIGUES, R. B.; ALMEIDA, F. S. Guia de herbicidas. 4.ed. Londrina, 1998. 648p.

SELLECK, G. W. Environmental factors and herbicidal performance in potatoes on Long Island. In: MEETING WEED SCIENCE SOCIETY OF AMÉRICA, 1978, Norfolk. Abstracts... Norfolk: WSSA, 1978. p. 28-29.

SHARPE, N.; CHIRITA, N.; BUDOI, G.; HOGEA, C. Research works on both selectivity and efficacy of the herbicides dimethenamid, alachlor and pendimenthalin (mixed with metribuzin or linuron) for potato crop. In: INTERNATIONAL SYMPOSIUM ON CROP PROTECTION, 46 ${ }^{\mathrm{TH}}$, 1994, Belgium. Proceedings... Gent: BCPC, 1994. v.59, n.3b, p. 1361-1365.
VELINI, E. D.; MARTINS, D.; MANOEL, L. A.; MATSUOKA S.; TRAVAIN, J. C.; CARVALHO, J. C. Avaliação da seletividade da mistura de oxyfluorfen e ametryne, aplicada em pré ou pós-emergência, a dez variedades de cana-de-açúcar (cana-planta). Planta Daninha, Viçosa, v. 18 , n. 1, p.123-134, 2000. 